\title{
Can vitamin D help in achieving asthma control? Vitamin D "revisited": an updated insight
}

The authors declare no financial disclosure

\begin{abstract}
Asthma - a prolonged respiratory disease related with hyper-responsiveness and increased inflammation of airways; affects millions peoples worldwide. Vitamin D possess anti-inflammatory and immunomodulatory activities. Its deficiency (the level less than $20 \mathrm{ng} / \mathrm{mL}$ in the serum) is found to be related to occurrence of pulmonary diseases including bacterial and viral infections and asthma. Some studies indicate that low levels of vitamin $D$ in the serum are related to reduced lung function and increased airway inflammation as well as overall poor results in asthmatic patients. Thus, it provides positive relation between vitamin $\mathrm{D}$ and asthma. Increased prevalence of asthma over the past decades causes elevated interest in vitamin D supplementation that is even reported as a ,potential therapeutic option". Unfortunately, results of clinical trials are inconsistent and do not provide supportive information about positive role of vitamin D in asthma. Little or even no effect of supplementation of vitamin D in improvement of onset, symptoms or progression of asthma was found in comprehensive interventional studies in adults, children and pregnant woman. This review critically summarized the last years evidence of a relation between vitamin $\mathrm{D}$ and asthma in adults, children and pregnant women.
\end{abstract}

Key words: asthma, vitamin D, vitamin D deficiency, vitamin D supplementation

Adv Respir Med. 2018; 86: 103-109

\section{Introduction}

In the past, vitamin $\mathrm{D}$ was only associated with its classical, skeletal action related to regulation of bone homeostasis. Nowadays, its pleiotropic activity (vitamin D plays a role in many physiological processes) is also known [1]. Vitamin D deficiency affects approximately one billion people worldwide and is connected with development of many diseases including asthma [2]. This review critically discusses the relation between vitamin $\mathrm{D}$ and asthma in children, pregnant women and adults.

\section{Vitamin D synthesis, metabolism and mechanism of action}

Humans may obtain vitamin D via two major sources: endogenous synthesis in the skin after
UVB light exposure and diet (intake of vitamin $\mathrm{D}$ rich products such as fish, fish oils, egg yolk, liver and dietary supplements) [3, 4]. In the skin, 7-dehydrocholesterol is converted to previtamin D due to action of UVB rays and then transformed to cholecalciferol via thermally induced isomerization. Afterwards, vitamin $\mathrm{D}$ is hydroxylated to 25-hydroxyvitamin D (25[OH]D) - the circulating metabolite of vitamin $\mathrm{D}$ in the liver. The binding of 25(OH)D to vitamin D-binding protein (VDBP) ensures its stability in the circulation [3, $5,6]$. In the kidneys, $25[\mathrm{OH}] \mathrm{D}$ is hydroxylated to 1,25 dihydroxy-vitamin $\mathrm{D}\left(1,25[\mathrm{OH}]_{2} \mathrm{D}\right)$ - active form of vitamin $\mathrm{D}$; calcitriol; by acting $1-\alpha$-hydroxylase (cytochrome P-450 [CYP] 27B1) enzyme. $1,25(\mathrm{OH})_{2} \mathrm{D}$ binds to vitamin $\mathrm{D}$ receptor (VDR) in the cytoplasm to show its intracellular biological activity. The $1,25(\mathrm{OH})_{2} \mathrm{D}+$ VDR complex forms a heterodimer with retinoid $\mathrm{X}$ receptor

Address for correspondence: Rafał Pawliczak, Immunopathology Department; Medical University of Lodz, Zeligowskiego 7/9, 90-752 Lodz,

e-mail: rafal.pawliczak@csk.umed.lodz.pl

DOI: 10.5603/ARM.2018.0015

Received: 10.10 .2017

Copyright (C) 2018 PTChP

ISSN 2451-4934 
(RXR). Translocation of $1,25(\mathrm{OH})_{2} \mathrm{D}+\mathrm{VDR}+$ RXR to the nucleus and its subsequent binding to vitamin D response element (VDRE) leads to the repression or activation of vitamin D-dependent gene transcription $[3,4,6,7]$.

\section{What may determine the level of vitamin D?}

The concentration of vitamin $\mathrm{D}$ in the serum less than $20 \mathrm{ng} / \mathrm{mL}$ (less than $50 \mathrm{nmol} / \mathrm{L}$ ) is defined as vitamin $\mathrm{D}$ deficiency, whereas the concentration of vitamin $\mathrm{D}$ in the serum higher than $20 \mathrm{ng} / \mathrm{ml}$ but less than $30 \mathrm{ng} / \mathrm{mL}$ is defined as vitamin D insufficiency [8-10]. The results of epidemiological studies indicate that there are many factors which may determine the concentration of 25(OH)D in the serum, including age, sun exposure, diet, pigmentation of the skin color (people with lighter skin have higher levels of vitamin $\mathrm{D}$ as compared to people with heavily pigmented skin), sex, vitamin D fortification as well as latitude of residence (lower latitudes create an increased opportunity for endogenous synthesis of vitamin D in the skin) [4]. Despite the fact that research carried out in the past decades provided more valuable information about vitamin $\mathrm{D}$ and its mechanism of action, both insufficiency as well as deficiency of vitamin $D$ have increased in the population worldwide. Some studies indicate that intake of multivitamins and food fortification do not decrease the prevalence of vitamin $\mathrm{D}$ deficiency in developing countries, even in sunny areas. It may be associated with lifestyle changes such as reduced sunlight exposure, increased indoor activities, dietary changes and the use of sunscreen $[8,9]$. Nowadays, recommended doses of vitamin D for fortification of food are not sufficient and adequate for prevention of vitamin $\mathrm{D}$ deficiency and insufficiency. Additionally, there are other factors that may affect the levels of $25(\mathrm{OH}) \mathrm{D}$ in the serum, such as sex, race, single nucleotide polymorphisms (SNPs) in VDRs and VDBPs and pharmacogenic factors in metabolism of vitamin D [5].

\section{The role of vitamin $D$ in asthma pathogenesis}

Vitamin D acts as a potential immunomodulator of inflammatory cells involved in asthma pathogenesis. The Figure 1 summarizes the immunomodulatory activity of vitamin $\mathrm{D}$ in asthma-related inflammatory cells.

The role of vitamin $\mathrm{D}$ in the asthma pathogenesis still attracts attention of many researchers. The importance of vitamin D in asthma background has been the main point of the studies carried out by several research groups in the past 2 decades.

Phospholipases $\mathrm{A}_{2}\left(\mathrm{PLA}_{2} \mathrm{~s}\right)$ are enzymes that provide arachidonic acid through hydrolyzation of phospholipids. Arachidonic acid is a substrate for production of lipid inflammatory mediators (eicosanoids) involved in asthma pathogenesis [11]. Unpublished results of our studies indicate that $1,25(\mathrm{OH})_{2} \mathrm{D}_{3}$ may decrease expression of $\mathrm{PLA}_{2} \mathrm{~S}$ via Ubiquitin $\mathrm{C}$, NF- $\kappa \mathrm{B}$ signaling pathway (studies were carried out in the Immunopathology Department (2016/2017), Medical University of Lodz, Poland).

Some studies have shown a link between asthma symptoms as well as poor lung function and vitamin D deficiency in asthma patients [9, 12]. Several genetic studies identified the correlation

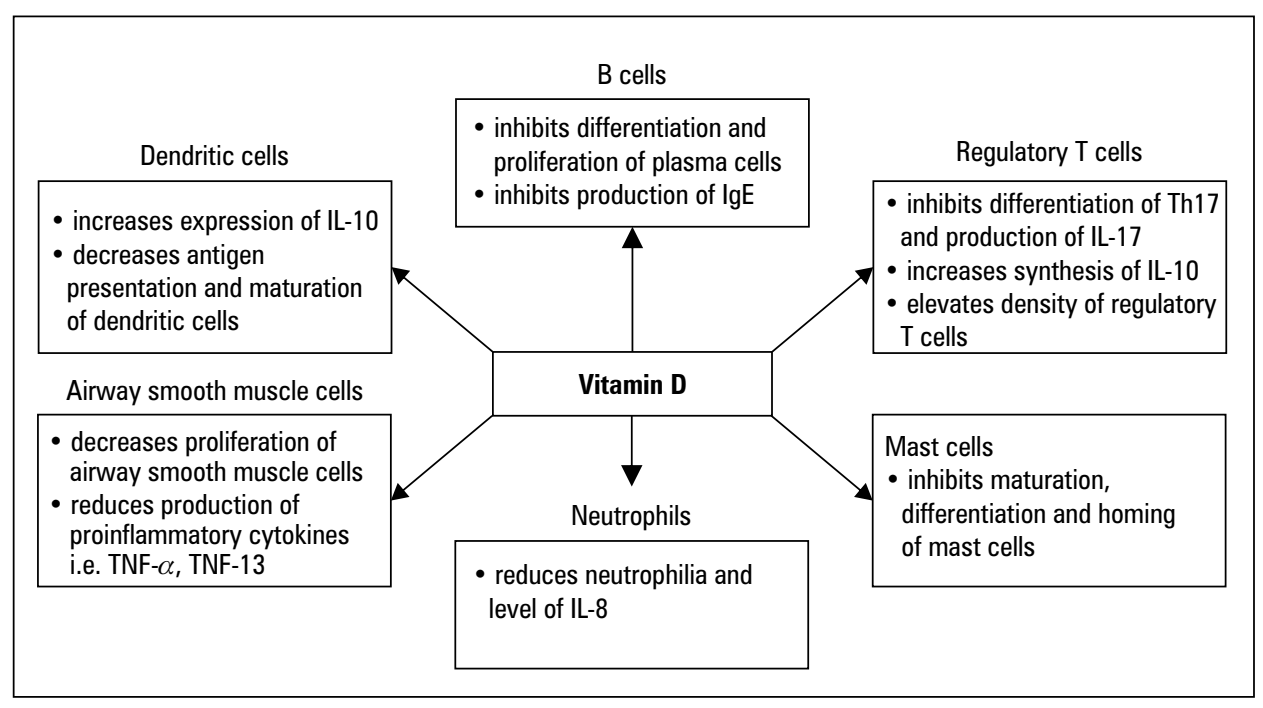

Figure 1. Immunomodulatory activity of vitamin $D$ on inflammatory cells involved in pathogenesis of asthma $[1,5]$ 
between some gene polymorphisms of VDBP and VDR and elevated susceptibility to asthma [13]. The results of meta-analysis and epidemiological studies have shown that decreased serum levels of vitamin $\mathrm{D}$ in children are related to decreased function of the lungs; an elevated risk for asthma, exacerbations and symptoms in asthma children [10]. Moreover, low maternal levels of vitamin $\mathrm{D}$ and decreased intake of vitamin $\mathrm{D}$ during pregnancy may be associated with increased likelihood of wheezing in the offspring $[8,9]$. Findings from many studies have indicated that vitamin D may act on structural cells of the airways as well as both innate and adaptive immune systems` cells. In addition, vitamin D deficiency promotes inflammation, however, vitamin D supplementation reduces these effects $[4,7,12,14$, 15]. Unfortunately, results obtained from clinical trials are not consistent. The role of vitamin $\mathrm{D}$ supplementation as an adjunct or alternative therapy method in patients with asthma is still debatable.

\section{Vitamin D and asthma — an overview of data from the last years}

\section{Children}

The number of children suffering from asthma has increased in the past 5 decades. Nowadays, $\sim 6.3$ million children worldwide have asthma - one of the most common chronic diseases among children aged $<18$. An increased number of children with asthma may be the result of environmental microbial changes and urbanization [16].

The majority of vitamin $\mathrm{D}$ functions are mediated by VDR. Some VDR gene SNPs change the functions of vitamin $\mathrm{D}$ and are related to different pathological conditions. The relation between the effect of vitamin D and VDR SNPs on asthma has been also proposed.

SNPs in the VDR gene and vitamin D deficiency has been correlated with asthma development. The measurements of 25(OH)D levels and analysis of SNPs: ApaI, FokI and TaqI were carried out to determine the relation between the levels of vitamin D and frequency of following SNPs in the VDR gene in persistent asthma children and controls. The significant differences between the FokI $\mathrm{C}$ allele and vitamin D insufficiency were found. Moreover, no dissimilarities between both ApaI, TaqI and the levels of vitamin D were shown [17].

Zhao et al. [18] summarized the relationship between polymorphisms of the VDR gene: FokI, BsmI, TaqI, ApaI and childhood asthma in me- ta-analysis. FokI polymorphism may play a role in white pediatric patients with asthma, whereas ApaI polymorphism may be related to childhood asthma. No relation was found between Taq I polymorphism and a risk of asthma in children. BsmI polymorphism may slightly affect development of childhood asthma.

Some studies have found association between a decreased level of vitamin $\mathrm{D}$ and exacerbation of symptoms in asthmatic children $[4,10$, 19, 20]. The results of the Puerto Rican children study have shown that vitamin D insufficiency may be associated with elevated odds of asthma exacerbations independently of time spent outdoors, severity and control markers of disease, atopy, African racial ancestry [21]. A significantly decreased level of vitamin $D$ in the asthmatic children serum, as compared to the control group, was also found in the study based on the analysis of the level of 25(OH)D in 1-4 year-old preschoolers with asthma and in healthy subjects. In the group of children with vitamin $\mathrm{D}$ deficiency, the total number of exacerbations in the previous year was much higher as compared to the group of children with vitamin D sufficiency. The probability of controlled asthma was lower in the vitamin $\mathrm{D}$ deficiency group and higher in the vitamin $\mathrm{D}$ sufficiency group. Thus, the obtained results have shown a positive relation between asthma control and vitamin D level in the serum [22]. Similarly, a cross-sectional survey has shown a positive correlation between the level of vitamin $\mathrm{D}$ and asthma control in Italian children. Vitamin D deficiency and insufficiency have been related with reduced asthma control and pulmonary function in a study population from northern Italy [23]. Significant improvement of asthma control in the vitamin D group ( 54 children), as compared to placebo group ( 35 children), was observed in Japanese schoolchildren. Short-term, low-dose supplementation of vitamin $\mathrm{D}$ as addition to standard asthma therapy may improve asthma control in schoolchildren [24].

The results of a double-blind, randomized, placebo-controlled study have shown that vitamin D supplementation may rapidly elevate the level of serum $25(\mathrm{OH}) \mathrm{D}$ in asthmatic preschool patients. All of preschoolers in the study group (100\% of the subjects) had level of $\geq 75 \mathrm{nmol} / \mathrm{L}$ ( $>$ $30 \mathrm{ng} / \mathrm{mL}$ ) serum 25(OH)D after 3 months of supplementation [5, 25]. Similarly, supplementation of $2000 \mathrm{IU} / \mathrm{d}$ vitamin D for 15 weeks lead to an increased level of serum 25(OH)D and a reduced number of asthma-related missed schooldays in children from Ireland. Interestingly, no changes in 
parameters of asthma in comparison to the placebo group were found [26]. Improvement in asthma control was also revealed in children supplemented with $800 \mathrm{IU} / \mathrm{d}$ vitamin D for 2 months - according to the results of the study from Japan assessing severity and frequency of asthma [24]. Moreover, vitamin D supplementation was proposed as an adjunct to standard asthma treatment [27].

Asthma is a heterogeneous pulmonary disease, thus the approach to achieve its better control and to stop its progression should require more targeted treatment in accordance with different phenotypes of the condition. Numerous studies have been carried out to delineate phenotypes of asthma in children [28]. Better understanding of the disease phenotypes in youngsters may help in identifying potential targets for the prevention of progression and development of asthma in children. It is not excluded that vitamin D is a potential promising candidate for such strategy.

The findings from several studies have provided no evidence of correlation between vitamin D insufficiency or deficiency and overall poor outcomes in patients with asthma. No relation between the level of vitamin $\mathrm{D}$ and airway inflammation, airway reactivity as well as allergy has been found in non-obese, not receiving anti-inflammatory treatment children with asthma [20]. The findings from meta-analysis have shown that the relation between the level of vitamin $\mathrm{D}$ and the incidence of asthma, asthma control and lung functions are inconclusive. Non-asthmatic children have an upper level of $25(\mathrm{OH}) \mathrm{D}$ as compared to asthmatic children. However, the studies focused on a linking correlation between the level of 25(OH)D and lung functions; asthma incidence and control had mixed results. The author of meta-analysis also highlighted strengths (rigorous data analysis and extraction, broad search strategy) and limitations (i.e. significant heterogeneity among studies based on different methods of vitamin $\mathrm{D}$ measurement in various researches) of review [29]. Interestingly, Dogru et al. [30] observed that vitamin $\mathrm{D}$ deficiency is common in both control and asthma patients. However, the number of exacerbations and severity of disease is associated with vitamin D level. According to the World Allergy Organization, there is no support for hypothesis that vitamin $\mathrm{D}$ supplementation may reduce the risk of allergic diseases development in children. Moreover, it has been suggested that vitamin D supplementation in pregnant women, healthy infants and breastfeeding mothers has not prevented allergic diseases [31].
Results obtained from clinical trials are not conclusive. Additional studies must be performed in order to determine the role of vitamin D deficiency or insufficiency in the onset, appearance of symptoms and control of asthma in children.

\section{Pregnant women}

Several studies have been conducted to find out how maternal diet may be related to development of asthma in children. The results of a prospective cohort study (1724 children from Spain) have shown a relation between increased maternal vitamin $D$ intake and decreased risk of infections of the lower respiratory tract in children during first year of life but no relation with asthma and wheezing [32]. Camargo et al. [33] have observed an inverse relation between cordblood 25(OH)D level and childhood wheezing as well as respiratory infection risk but no such relation was found with asthma [33]. The level of fetal and maternal 25(OH)D at birth, midgestation and airway resistance of 6-year-old offspring was measured in order to evaluate the relation between the level of 25(OH)D and childhood asthma as well as lung function. No relation was found between 25(OH)D level at midgestation and airway resistance in 6-year-old offspring. However, a decreased $25(\mathrm{OH}) \mathrm{D}$ level at birth may be related to increased airway resistance in childhood [34]. Zosky et al. [35] showed the relationship between maternal vitamin D deficiency (16-20-week gestation) and impaired function of the lung as well as development of asthma at the age of 6 [35].

The results of the study from Taiwan have shown significant relations between maternal and cord blood level of 25(OH)D and a decreased level of vitamin $\mathrm{D}$ in children with vitamin $\mathrm{D}$ deficient mother. Moreover, maternal vitamin D deficiency may be also associated with allergen sensitization prevalence in < 2-year-old children [36].

The results obtained from a double-blind, randomized, parallel-group, placebo-controlled trial have revealed that supplementation of women (1000 IU/2000 IU) and infants (400 IU/800 IU) decreased sensitization of children to mites at 18 months [37].

\section{Adults}

The VDR gene may be determined as a pleiotropic gene related to multiple inflammatory, autoimmune and allergy diseases. The results of a meta-analysis have indicated that polymorphisms of the VDR gene may be associated with increased asthma susceptibility. VDR polymor- 
phisms had been also proposed as option for consideration as biomarkers for susceptibility of asthma [38]. Shahin et al. [39] have observed a decreased level of vitamin $\mathrm{D}$ in patients with asthma as compared to controls (70 adult patients with asthma [vitamin D level: $19.88 \pm 9.6 \mathrm{ng} . \mathrm{mL}$ ]; 20 controls [vitamin D level: $33.5 \pm 6.1 \mathrm{ng} / \mathrm{mL}$ ]).

A decreased level of serum 25(OH)D (less than $30 \mathrm{ng} / \mathrm{mL}$ ) is common in adult patients with uncontrolled and/or severe asthma. Moreover, the patients with eosinophilic disease or treated with oral corticosteroids have an increased risk of vitamin D insufficiency [40]. The effect of using medium and small doses of inhaled glucocorticosteroids on skeletal mineral density have not been noticed. However, higher doses of inhaled glucocorticosteroids may cause bone mineralization disorders [41]. In the group of patients treated with high doses of budesonide together with vitamin $\mathrm{D}$, inhibition of the resorption process in bones was observed while there were no changes in the concentrations of backbone markers [42].

A low level of vitamin D (less than $20 \mathrm{ng} /$ $\mathrm{mL}$ ) is related to an elevated risk of asthma in adults and adolescence - as it has been reported by the study from Canada [43]. In adult Turkish patients with asthma, lower levels of vitamin $\mathrm{D}$ were related to poor asthma control, pulmonary function and lower absolute $\mathrm{FEV}_{1}$ values [44].

Interestingly, the study of the Danish population (30-60-year-old) has shown no effect of serum vitamin $\mathrm{D}$ level on asthma and allergy development in adults [45]. Similarly, a case-control study also has identified no relation between a lower vitamin $\mathrm{D}$ level and asthma development [46].

The level of $1,25(\mathrm{OH})_{2} \mathrm{D}, 25(\mathrm{OH}) \mathrm{D}$ and VDBP increased in BALF 24 hours after allergen challenge [47]. In Korean adults, a decreased level of $25(\mathrm{OH}) \mathrm{D}$ was positively correlated with the concentration of total IgE. A significantly lower level of serum 25(OH)D was observed in patients with a history of atopic dermatitis or asthma as compared to healthy controls [48]. The findings obtained from a retrospective analysis have shown that vitamin D sufficiency is related to reduction of asthma exacerbations and emergency department visits. Vitamin D was proposed as a modifiable risk factor for asthma exacerbations` severity. However, the obtained results have not confirmed the outcome of other studies presenting a relation between vitamin $\mathrm{D}$ deficiency and reduced $\mathrm{FEV}_{1}$ or obesity. Symptomatic asthmatics may be limited by allergy or may avoid outdoor physical activities, thus denying sunlight exposure and endogenous synthesis of vitamin D.
Therefore, it may be hypothesized that the occurrence of asthma may be casual of vitamin D deficiency and not the other way around. Because of this theory, it would be expected that patients with severe asthma would have further decreased level of vitamin D, however, it was not observed in the study population. Moreover, it may be possible that the cause of vitamin $\mathrm{D}$ deficiency is multifactorial and not related only to limited sun exposure [49]. A cross-sectional, multicenter study of the United Kingdom population has shown that adult corticosteroid-treated patients with asthma have a decreased status of vitamin D related to nonwhite ethnicity, non-use of vitamin D supplement, unemployment, higher body mass index but not genetic determinants [50]. Similarly, no significant relation between serum level of vitamin $D$ and prevalence of asthma, atopy and wheezing in adults was found in the study of the Denmark population either [45].

Vitamin D and Lung Function Decline in Adults with Asthma (HUNT) study in Norway indicated greater declines in $\mathrm{FEV}_{1} / \mathrm{FVC}$ ratio FVC and $\mathrm{FEV}_{1}$ in patients with a decreased level of $25(\mathrm{OH}) \mathrm{D}$ as compared to patients with a high level of vitamin D. Basing on the obtained results, a poor relation between vitamin D insufficiency and decline in lung function was found in adult asthma patients [51].

Viral infections of the airways play an important role in exacerbations, progression and onset of asthma [52]. The importance of vitamin $\mathrm{D}$ in the prevention of upper respiratory tract infections or exacerbations was determined in a placebo-controlled, randomized double-blind trial from London. Asthma patients were supplemented with vitamin D for 1 year (6 doses, every 2 months). The obtained results have shown no effect of vitamin D supplementation on upper respiratory tract infections or exacerbations [53]. Vitamin D supplementation does not support the reduction of frequency and severity of cold in corticosteroid-inhaled mild to moderate asthma patients [54].

The results of the studies aimed at determination of association between vitamin $\mathrm{D}$ and asthma are still inconclusive. To better determine the nature of vitamin D-asthma relation, more targeted studies need to be conducted.

\section{Conclusion}

The number of people with vitamin $\mathrm{D}$ deficiency is still growing despite the increased interest and knowledge about certain food fortification 
and mechanism of vitamin D action. The potential role of vitamin $D$ in the pathogenesis of asthma is still not fully known. The results obtained from the studies focused on the role of vitamin $\mathrm{D}$ in the asthma pathogenesis and beneficial effects of vitamin D in asthma patients are inconclusive. Even though vitamin D supplementation was proposed as adjunct therapy option for asthma patients, the results of some clinical trials have identified very little or even barely no efficacy of vitamin D supplementation in improvement of onset and symptoms in asthma patients. Despite the fact that the studies carried out in these fields provide many valuable information on vitamin $\mathrm{D}$-asthma relation, some studies have indicated no effect of vitamin D supplementation on exacerbation and asthma control. It is highly possible that these studies may have some limitations, i.e. variations in vitamin $\mathrm{D}$ dosage, duration of trials and limited sample sizes, all contributing to the observed results. Moreover, the consensus between determination of "vitamin D deficiency" and "vitamin D insufficiency" level is needed. The prevalence of vitamin D insufficiency and deficiency differs from "country to country". Thus, there is a need for randomized "well-conducted" trials of vitamin D supplementation (different vitamin $\mathrm{D}$ doses and supplementation duration) to estimate the effectiveness of vitamin D supplementation in asthma control and lung function. In future research, the optimal dose of vitamin $D$ in various populations distinguished by age, ethnicity, sex, cultural practices, phenotypes of asthma, factors playing a role in absorption of vitamin $\mathrm{D}$ should be taken into consideration during design of the studies. Thus, despite the inconclusive results of clinical trials, it is highly probable that vitamin D can help in achieving asthma control due to its immunomodulatory effects on inflammatory cells involved in asthma pathogenesis and its anti-inflammatory activities.

Currently, it is impossible to determine whether vitamin D supplementation improves treatment and control of asthma. As mentioned before, research data concerning the subject is inconclusive but this standpoint may change in the future once more refined research is carried out.

\section{Conflict of interest}

The authors declare no conflict of interest.

\section{References:}

1. Szymczak I, Pawliczak R. The Active Metabolite of Vitamin D3 as a Potential Immunomodulator. Scand J Immunol. 2016; 83(2): 83-91, doi: 10.1111/sji.12403, indexed in Pubmed: 26678915.
2. Holick MF. Vitamin D deficiency. N Engl J Med. 2007; 357(3): 266-281, doi: 10.1056/NEJMra070553, indexed in Pubmed: 17634462 .

3. Konstantinopoulou S, Tapia IE. Vitamin D and the lung. Paediatr Respir Rev. 2017; 24: 39-43, doi: 10.1016/j. prrv.2016.10.009, indexed in Pubmed: 27964949.

4. Kerley CP, Elnazir B, Faul J, et al. Vitamin D as an adjunctive therapy in asthma. Part 2: A review of human studies. Pulm Pharmacol Ther. 2015; 32: 75-92, doi: 10.1016/j. pupt.2015.02.010, indexed in Pubmed: 25749414.

5. Hall SC, Agrawal DK. Vitamin D and Bronchial Asthma: An Overview of Data From the Past 5 Years. Clin Ther. 2017; 39(5): 917-929, doi: 10.1016/j.clinthera.2017.04.002, indexed in Pubmed: 28449868.

6. Mirzakhani H, Al-Garawi A, Weiss ST, et al. Vitamin D and the development of allergic disease: how important is it? Clin Exp Allergy. 2015; 45(1): 114-125, doi: 10.1111/cea.12430, indexed in Pubmed: 25307157.

7. Hall SC, Fischer KD, Agrawal DK. The impact of vitamin D on asthmatic human airway smooth muscle. Expert Rev Respir Med. 2016; 10(2): 127-135, doi: 10.1586/17476348.2016.1128326, indexed in Pubmed: 26634624

8. Thacher TD, Clarke BL. Vitamin D insufficiency. Mayo Clin Proc. 2011; 86(1): 50-60, doi: 10.4065/mcp.2010.0567, indexed in Pubmed: 21193656.

9. Bozzetto S, Carraro S, Giordano G, et al. Asthma, allergy and respiratory infections: the vitamin D hypothesis. Allergy. 2012; 67(1): 10-17, doi: 10.1111/j.1398-9995.2011.02711.x, indexed in Pubmed: 21933195.

10. Gupta A, Bush A, Hawrylowicz C, et al. Vitamin D and asthma in children. Paediatr Respir Rev. 2012; 13(4): 236-43; quiz 243, doi: 10.1016/j.prrv.2011.07.003, indexed in Pubmed: 23069123.

11. Pniewska E, Pawliczak R. The involvement of phospholipases A2 in asthma and chronic obstructive pulmonary disease. Mediators Inflamm. 2013; 2013: 793505, doi: 10.1155/2013/793505, indexed in Pubmed: 24089590.

12. Yawn J, Lawrence LA, Carroll WW, et al. Vitamin D for the treatment of respiratory diseases: is it the end or just the beginning? J Steroid Biochem Mol Biol. 2015; 148: 326-337, doi 10.1016/j.jsbmb.2015.01.017, indexed in Pubmed: 25625665.

13. Tizaoui K, Berraies A, Hamdi B, et al. Association of vitamin $\mathrm{D}$ receptor gene polymorphisms with asthma risk: systematic review and updated meta-analysis of case-control studies. Lung. 2014; 192(6): 955-965, doi: 10.1007/s00408-014-9648-8, indexed in Pubmed: 25267113.

14. Berraies A, Hamzaoui K, Hamzaoui A. Link between vitamin D and airway remodeling. J Asthma Allergy. 2014; 7: 23-30, doi: 10.2147/JAA.S46944, indexed in Pubmed: 24729717.

15. Barragan M, Good M, Kolls JK. Regulation of Dendritic Cell Function by Vitamin D. Nutrients. 2015; 7(9): 8127-8151, doi: 10.3390/nu7095383, indexed in Pubmed: 26402698.

16. Smits HH, van der Vlugt LE, von Mutius E, et al. Childhood allergies and asthma: New insights on environmental exposures and local immunity at the lung barrier. Curr Opin Immunol. 2016; 42: 41-47, doi: 10.1016/j.coi.2016.05.009, indexed in Pubmed: 27254380.

17. Einisman H, Reyes ML, Angulo J, et al. Vitamin D levels and vitamin $\mathrm{D}$ receptor gene polymorphisms in asthmatic children: a case-control study. Pediatr Allergy Immunol. 2015; 26(6): 545-550, doi: 10.1111/pai.12409, indexed in Pubmed: 26011658.

18. Zhao DD, Yu DD, Ren QQ, et al. Association of vitamin D receptor gene polymorphisms with susceptibility to childhood asthma: A meta-analysis. Pediatr Pulmonol. 2017; 52(4): 423429, doi: 10.1002/ppul.23548, indexed in Pubmed: 27551963.

19. Hollams EM. Vitamin D and atopy and asthma phenotypes in children. Curr Opin Allergy Clin Immunol. 2012; 12(3): 228-234, doi: 10.1097/ACI.0b013e3283534a32, indexed in Pubmed: 22475998.

20. Dabbah H, Bar Yoseph R, Livnat G, et al. Bronchial Reactivity, Inflammatory and Allergic Parameters, and Vitamin D Levels in Children With Asthma. Respir Care. 2015; 60(8): 1157-1163, doi: 10.4187/respcare.03763, indexed in Pubmed: 25899478. 
21. Brehm JM, Acosta-Pérez E, Klei L, et al. Vitamin D insufficiency and severe asthma exacerbations in Puerto Rican children. Am J Respir Crit Care Med. 2012; 186(2): 140-146, doi: 10.1164/rccm.201203-0431OC, indexed in Pubmed: 22652028.

22. Turkeli A, Ayaz O, Uncu A, et al. Effects of vitamin D levels on asthma control and severity in pre-school children. Eur Rev Med Pharmacol Sci. 2016; 20(1): 26-36, indexed in Pubmed: 26813450.

23. Chinellato I, Piazza M, Sandri M, et al. Vitamin D serum levels and markers of asthma control in Italian children. J Pediatr. 2011; 158(3): 437-441, doi: 10.1016/j.jpeds.2010.08.043, indexed in Pubmed: 20870246.

24. Tachimoto H, Mezawa H, Segawa T, et al. Improved control of childhood asthma with low-dose, short-term vitamin D supplementation: a randomized, double-blind, placebo-controlled trial. Allergy. 2016; 71(7): 1001-1009, doi: 10.1111/all.12856, indexed in Pubmed: 26841365.

25. Jensen ME, Mailhot G, Alos N, et al. Vitamin D intervention in preschoolers with viral-induced asthma (DIVA): a pilot randomised controlled trial. Trials. 2016; 17(1): 353, doi: 10.1186/ s13063-016-1483-1, indexed in Pubmed: 27456232.

26. Kerley CP, Hutchinson K, Cormican L, et al. Vitamin D3 for uncontrolled childhood asthma: A pilot study. Pediatr Allergy Immunol. 2016; 27(4): 404-412, doi: 10.1111/pai.12547, indexed in Pubmed: 26845753.

27. Yadav M, Mittal K. Effect of vitamin D supplementation on moderate to severe bronchial asthma. Indian J Pediatr. 2014; 81(7): 650-654, doi: 10.1007/s12098-013-1268-4, indexed in Pubmed: 24193954.

28. Reddy MB, Covar RA. Asthma phenotypes in childhood. Curr Opin Allergy Clin Immunol. 2016; 16(2): 127-134, doi: 10.1097/ACI.0000000000000252, indexed in Pubmed: 26859369.

29. Jat KR, Khairwa A. Vitamin D and asthma in children: A systematic review and meta-analysis of observational studies. Lung India. 2017; 34(4): 355-363, doi: 10.4103/0970-2113.209227, indexed in Pubmed: 28671167.

30. Dogru M, Kirmizibekmez H, Yesiltepe Mutlu RG, et al. Clinical effects of vitamin D in children with asthma. Int Arch Allergy Immunol. 2014; 164(4): 319-325, doi: 10.1159/000366279, indexed in Pubmed: 25277142.

31. Yepes-Nuñez JJ, Fiocchi A, Pawankar R, et al. World Allergy Organization-McMaster University Guidelines for Allergic Disease Prevention (GLAD-P): Vitamin D. World Allergy Organ J. 2016; 9: 17, doi: 10.1186/s40413-016-0108-1, indexed in Pubmed: 27274360.

32. Morales E, Romieu I, Guerra S, et al. INMA Project. Maternal vitamin $\mathrm{D}$ status in pregnancy and risk of lower respiratory tract infections, wheezing, and asthma in offspring. Epidemiology. 2012; 23(1): 64-71, doi: 10.1097/EDE.0b013e31823a44d3, indexed in Pubmed: 22082994.

33. Camargo CA, Ingham T, Wickens K, et al. New Zealand Asthma and Allergy Cohort Study Group. Cord-blood 25-hydroxyvitamin D levels and risk of respiratory infection, wheezing, and asthma. Pediatrics. 2011; 127(1): e180-e187, doi: 10.1542/ peds.2010-0442, indexed in Pubmed: 21187313.

34. Gazibara T, den Dekker HT, de Jongste JC, et al. Associations of maternal and fetal 25-hydroxyvitamin D levels with childhood lung function and asthma: the Generation R Study. Clin Exp Allergy. 2016; 46(2): 337-346, doi: 10.1111/cea.12645, indexed in Pubmed: 26399470.

35. Zosky GR, Hart PH, Whitehouse AJO, et al. Vitamin D deficiency at 16 to 20 weeks' gestation is associated with impaired lung function and asthma at 6 years of age. Ann Am Thorac Soc. 2014; 11(4): 571-577, doi: 10.1513/AnnalsATS.201312-423OC, indexed in Pubmed: 24601713.

36. Chiu CY, Huang SY, Peng YC, et al. Maternal vitamin D levels are inversely related to allergic sensitization and atopic diseases in early childhood. Pediatr Allergy Immunol. 2015; 26(4): 337-343, doi: 10.1111/pai.12384, indexed in Pubmed: 25847488.

37. Grant CC, Crane J, Mitchell EA, et al. Vitamin D supplementation during pregnancy and infancy reduces aeroallergen sensitization: a randomized controlled trial. Allergy. 2016; 71(9): 1325-1334, doi: 10.1111/all.12909, indexed in Pubmed: 27060679 .
38. Han JC, Du J, Zhang YJ, et al. Vitamin D receptor polymorphisms may contribute to asthma risk. J Asthma. 2016; 53(8): 790-800, doi: 10.3109/02770903.2016.1158267, indexed in Pubmed: 27088875.

39. Shahin M, El-lawah A, Amin A, et al. Study of serum vitamin D level in adult patients with bronchial asthma. Egyptian Journal of Chest Diseases and Tuberculosis. 2017; 66(1): 5-9, doi: 10.1016/j.ejcdt.2016.11.005.

40. Korn S, Hübner M, Jung M, et al. Severe and uncontrolled adult asthma is associated with vitamin D insufficiency and deficiency. Respir Res. 2013; 14: 25, doi: 10.1186/1465-992114-25, indexed in Pubmed: 23432854.

41. Chee C, Sellahewa L, Pappachan JM. Inhaled corticosteroids and bone health. Open Respir Med J. 2014; 8: 85-92, doi: 10.2174/1874306401408010085, indexed in Pubmed: 25674178.

42. Tse SM, Kelly HW, Litonjua AA, et al. Childhood Asthma Management Program Research Group. Corticosteroid use and bone mineral accretion in children with asthma: effect modification by vitamin D. J Allergy Clin Immunol. 2012; 130(1): 53-60.e4, doi: 10.1016/j.jaci.2012.04.005, indexed in Pubmed: 22608570 .

43. Niruban SJ, Alagiakrishnan K, Beach J, et al. Association between vitamin $\mathrm{D}$ and respiratory outcomes in Canadian adolescents and adults. J Asthma. 2015; 52(7): 653-661, doi: 10.3109/02770903.2015.1004339, indexed in Pubmed: 25563060.

44. Beyhan-Sagmen S, Baykan O, Balcan B, et al. Association Between Severe Vitamin D Deficiency, Lung Function and Asthma Control. Arch Bronconeumol. 2017; 53(4): 186-191, doi: 10.1016/j.arbres.2016.09.010, indexed in Pubmed: 28320552.

45. Thuesen BH, Heede NG, Tang L, et al. No association between vitamin $\mathrm{D}$ and atopy, asthma, lung function or atopic dermatitis: a prospective study in adults. Allergy. 2015; 70(11): 15011504, doi: 10.1111/all.12704, indexed in Pubmed: 26214285.

46. Devereux G, Wilson A, Avenell A, et al. A case-control study of vitamin D status and asthma in adults. Allergy. 2010; 65(5): 666-667, doi: 10.1111/j.1398-9995.2009.02220.x, indexed in Pubmed: 19845573.

47. Bratke K, Wendt A, Garbe K, et al. Vitamin D binding protein and vitamin $\mathrm{D}$ in human allergen-induced endobronchial inflammation. Clin Exp Immunol. 2014; 177(1): 366-372, doi: 10.1111/cei.12346, indexed in Pubmed: 24730464.

48. Kang JuW, Kim JH, Kim HJ, et al. Association of serum 25-hydroxyvitamin D with serum IgE levels in Korean adults. Auris Nasus Larynx. 2016; 43(1): 84-88, doi: 10.1016/j. anl.2015.06.010, indexed in Pubmed: 26209260.

49. Salas NM, Luo Li, Harkins MS. Vitamin D deficiency and adult asthma exacerbations. J Asthma. 2014; 51(9): 950-955, doi: 10.3109/02770903.2014.930883, indexed in Pubmed: 24926743.

50. Jolliffe DA, Kilpin K, MacLaughlin BD, et al. Prevalence, determinants and clinical correlates of vitamin D deficiency in adults with inhaled corticosteroid-treated asthma in London, UK. J Steroid Biochem Mol Biol. 2018; 175: 88-96, doi: 10.1016/j. jsbmb.2016.11.004, indexed in Pubmed: 27825992.

51. Brumpton BM, Langhammer A, Henriksen AH, et al. Vitamin D and Lung Function Decline in Adults With Asthma: The HUNT Study. Am J Epidemiol. 2016; 183(8): 739-746, doi: 10.1093/ aje/kwv243, indexed in Pubmed: 26994061.

52. Busse WW, Lemanske RF, Gern JE. Role of viral respiratory infections in asthma and asthma exacerbations. Lancet. 2010 376(9743): 826-834, doi: 10.1016/S0140-6736(10)61380-3, indexed in Pubmed: 20816549.

53. Martineau AR, Hanifa Y, Witt KD, et al. Double-blind randomised controlled trial of vitamin D3 supplementation for the prevention of acute respiratory infection in older adults and their carers (ViDiFlu). Thorax. 2015; 70(10): 953-960, doi: 10.1136/thoraxjnl-2015-206996, indexed in Pubmed: 26063508.

54. Denlinger LC, King TS, Cardet JC, et al. NHLBI AsthmaNet Investigators. Vitamin D Supplementation and the Risk of Colds in Patients with Asthma. Am J Respir Crit Care Med. 2016; 193(6): 634-641, doi: 10.1164/rccm.201506-1169OC, indexed in Pubmed: 26540136. 